\title{
Advice on running a 'TOOTH NIGHT'
}

\author{
Oliver Chapple BDS (St And), Chairman 27th Lincoln (1st Thorpe-on-the-hill) Scout Group, \\ offers some advice on teaching groups of youngsters about good oral health.
}

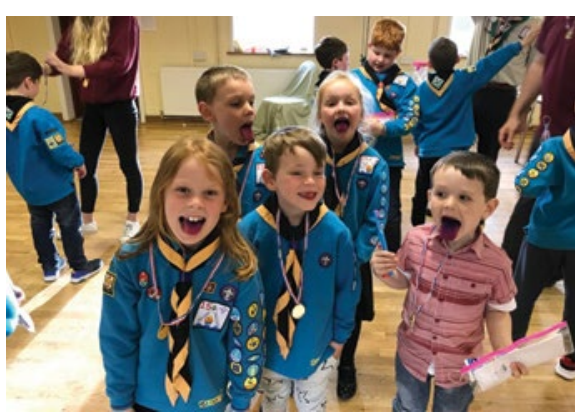

L here have been a number of excellent articles in the $B D J$ just recently about getting the tooth brushing message across to the younger generation. The BBC children's programme 'Hey Duggee' [The Tooth Brushing Badge; The Toothbrush Song; CBeebies] is a great motivator, especially when it ends with a 'Duggee Hug... it always brings a smile from everyone, but especially grandads and grandmas.

As a profession we have a responsibility to pass on the prevention message and to try to ensure the youngsters and children in our care have the very best chance of beautiful teeth, and for life. Often we will be approached by Brownies, Guides, Scouts, Cubs and other organisations to come along and do a 'toothy' evening or afternoon and this can be a truly terrifying prospect ... 30 or 40 wound-up children running around intent on mayhem and anarchy; who would volunteer to be subject to that?

However, it can be a satisfying and fun event, and with a little advice and careful planning, not as traumatic as it first appears.

Having another dental person with you can be a great help but don't forget about the demands of safeguarding when in contact with children. The teachers/leaders will be there to advise and protect you and keep you out of trouble.

Ground rules: children like to have simple rules and my first rule is when I would like quiet I raise my arm and smile widely. The children then have to raise their arms and smile broadly back. The first few times it takes a while for the ripple effect to catch on but soon there's an almost immediate response and you are faced with a slightly alarming forest of small arms, wildly grinning faces and silence. This is very successful and really rather fun.

1) Start the session by sitting down on the floor at the same level as the children. It's important to create a friendly atmosphere. Then establish the second rule: when a question is asked, if someone wants to answer, and they are all keen to answer, then they must put their hand up and wait to be picked. You've set the stage. prompting do all the speaking parts and act out their roles.

They knock on the door and go to report to reception; they are asked to take a seat, wait for the nurse to call them, say hello to the dentist ... the dentist counts teeth and says they're brushing well and gives them a badge. You can make this as simple or as complex as you think your audience will tolerate but I prefer to keep it light and easy.

The other children are quick to point out errors and give advice and generally this part tends to descend into a hub-bub that gets a little out of control; however, hold your arm high in the air and smile broadly. You will feel a bit 'Noddy' but surprise, surprise, order

\section{'Children have great fun pretending to be grown-ups and with a tiny amount of prompting do all the speaking parts and act out their roles'}

Questions you might ask:

Who's been to the dentist? Was the dentist a lady or a gentleman?

Was he/she nice? Did you get a badge?

What did the dentist do?

Was Mummy/Daddy with you when you went?

Did the dentist talk about tooth brushing?

Etc, etc, creating a scene that the children are all comfortable with.

2) Now we are going to play act what happens when we go to the dentist. (I use a couple of sets of mini-dentist dressing up clothes and pick volunteers to play the part of the receptionist/the other people in the waiting room/the patient/their mummy/ daddy/dentist and nurse. A tablecloth draped over a chair makes a very acceptable and quick 'dental chair')

Children have great fun pretending to be grown-ups and with a tiny amount of is resumed and we can have a question and answer session on what happened, why it was important and why you don't need to be nervous about your dental appointment.

3) For the next part a pack that the children can put their name on and can take away is a good idea. I suggest a toothbrush suitable to the age group, two disclosing tablets, toothpaste, a tooth brushing chart, and a two-minute egg timer.

This part of the session can get messy so copious amounts of napkins are useful to have around. All of the children are sat down with a paper cup, a toothbrush and a disclosing tablet in front of them, and in front of you, of course. It is good to have three or four mirrors scattered around so that the children can see what they are doing. It is useful to have a large mouth model to demonstrate tooth brushing and a large egg timer to monitor the time. Once the children 


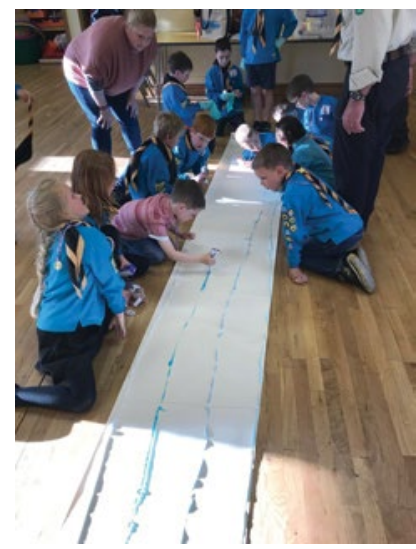

« all know what they have to do and for how long - two minutes - then it is time to start. All chew the tablet for 30 seconds then swish it around and look in the mirror. The noise level soon gets out of hand so arm up again! The big egg timer turns over and off we all go: brushing as demonstrated. After two minutes everyone can rinse out and then if you have the luxury of having a back-up, they then show the children the results and if they've done good then they get a medal ... and of course they've all 'done good'.

So far so good, but the evening hasn't finished yet and the children are keen to find out what is next on the agenda.

4) The research project is next. The task is to compare how much toothpaste is in various tubes (four) and various makes.

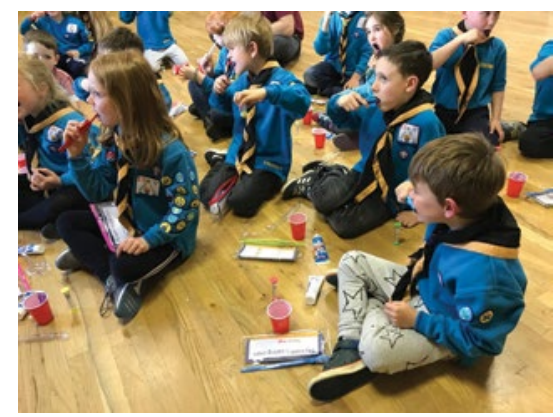

To do that a roll of wallpaper is spread out on the floor and the group is split into four teams. Each team member takes it in turn to squeeze out some toothpaste to end up with a continuous line. The line must be intact but the thinner it can be made the longer the line will be. This demands a huge amount of concentration and team effort and is taken very seriously. The results have been surprisingly consistent with the major brands all resulting in virtually the same measurement. The one brand that always comes out ahead by a long margin is a well-known sensitivity toothpaste. Why that is, is a mystery!

After the session is finished we need a summing up chat with questions on what has been learnt and whether anything will change or was it all known about before.

Your amazing assistant will have blown up balloons and attached them to the toothbrush pack with their name on for them to

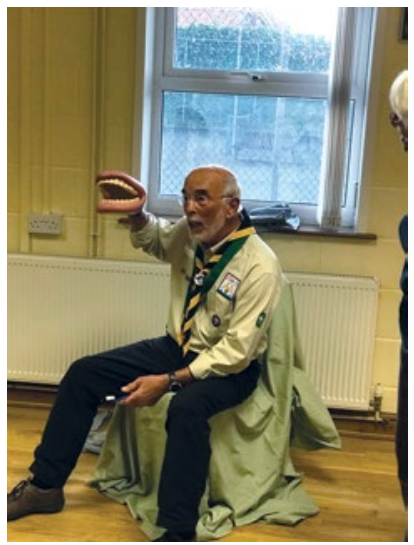

take home to show off what they've learnt to their long suffering parents.

Your fun evening has the potential to reach out to a large number of folk. With the 100 youngsters in my group that's nearly 200 parents, 300-400 grandparents and something like another 100 brothers and sisters, to say nothing of aunts and uncles etc. You will have planted some valuable seeds in young people's minds and that is amazingly worthwhile, so now you can go home and relish a decent dram or whatever is the tipple of choice because you also have 'done good'.

Thanks for advice and support to Heather Chapple BDS (St And), Jonathan Chapple BDS, MFDS RCS(Edin), MSc, MOrth RCS(Edin), FDS(Orth) RCS(Edin), Gemma Chapple MA and Carole Marlow EDH.

\section{Oral health in the curriculum is 'fantastic news'}

The Faculty of General Dental Practice (UK) has welcomed the inclusion of oral health in new statutory guidance on health education for schools in England. ${ }^{1}$

The UK was recently ranked the lowest of 13 countries for providing oral health education in schools, but the new guidance will require that both primary and secondary school pupils are taught about dental health, including the benefits of good oral hygiene, dental flossing and regular dental check-ups, the characteristics of a poor diet, and the risks associated with unhealthy eating, including tooth decay.

Health education is not currently mandatory in England, but will become a statutory duty when the guidance takes effect in September 2020, and schools are being encouraged to implement the new guidance in full from this year. Oral health is likely to

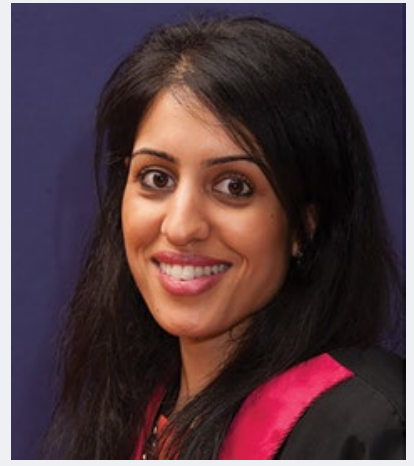

Roshni Karia

be taught as part of Personal, Social, Health and Economic (PHSE) lessons, which already take place in most state-funded schools in England.

Roshni Karia, Vice-Dean of FGDP(UK) and the Faculty's representative on Public Health England's Children's Oral Health Improvement Programme Board (pictured), said: 'Many children and parents are still unsure about what good oral health looks like, and are unaware of its importance for general health. As dentists we only get the chance to provide this message to those that come to see us, but unfortunately up to a third of school-aged children don't. So the inclusion of oral health in the school curriculum is fantastic news, and potentially a very significant moment in improving children's oral health'

\section{References}

1. Department for Education. Relationships education relationships and sex education (RSE) and Health Education. Statutory guidance for governing bodies, proprietors, head teachers, principals, senior leadership teams, teachers. 2019. Available at: https://assets.publishing.service.gov.uk/government/uploads/system/uploads/attachment_data/ file/805781/Relationships_Education__Relationships_and_Sex_Education__RSE__and_Health_ Education.pdf (accessed August 2019). 